\title{
Efficacy and safety of echinocandins versus triazoles for the prophylaxis and treatment of fungal infections: a meta-analysis of RCTs
}

\author{
J.-F. Wang $\cdot$ Y. Xue $\cdot$ X.-B. Zhu $・$ H. Fan
}

Received: 28 October 2014 / Accepted: 14 November 2014 / Published online: 14 December 2014

(C) The Author(s) 2014. This article is published with open access at Springerlink.com

\begin{abstract}
Echinocandins and triazoles were proven to be effective antifungal drugs against invasive fungal infections (IFI), which may cause significant morbidity and mortality in immunocompromised patients. The aim of this study was to compare the efficacy and safety between echinocandins and triazoles for the prophylaxis and treatment of fungal infections. PubMed, Embase, and the Cochrane Library were searched to identify relevant randomized controlled trials (RCTs) up to July 2014. The quality of trials was assessed with the Jadad scoring system. The primary outcomes of interest were treatment success, microbiological success, breakthrough infection, drug-related adverse events (AEs), withdrawals due to AEs, and all-cause mortality. Ten RCTs, involving 2,837 patients, were included, as follows: caspofungin versus fluconazole $(n=1)$, caspofungin versus itraconazole $(n=1)$, anidulafungin versus fluconazole $(n=1)$, micafungin versus fluconazole $(n=4)$, micafungin versus voriconazole $(n=2)$, and micafungin versus itraconazole $(n=$ 1). Echinocandins and triazoles showed similar effects in terms of favorable treatment success rate [relative risk $(\mathrm{RR})=1.02,95 \%$ confidence interval $(\mathrm{CI}), 0.97-1.08]$, microbiological success rate $(\mathrm{RR}=0.98,95 \% \mathrm{CI}, 0.90-1.15)$, breakthrough infection ( $\mathrm{RR}=1.09$; $95 \% \mathrm{CI}, 0.59-2.01)$, drugrelated $\mathrm{AEs}(\mathrm{RR}=0.94 ; 95 \% \mathrm{CI}, 0.71-1.15)$, and all-cause mortality $(\mathrm{RR}=0.85 ; 95 \% \mathrm{CI}, 0.66-1.10)$ in the prophylaxis and treatment of fungal infections. Additionally, echinocandins were more effective than triazoles for prophylaxis in patients undergoing hematologic malignancies or those who received hematopoietic stem cell transplantation
\end{abstract}

J.-F. Wang $\cdot$ Y. Xue $\cdot$ X.-B. Zhu $\cdot$ H. Fan $(\triangle)$

Department of Pharmacy, Sir Run Run Shaw Hospital, School of

Medicine, Zhejiang University, 3 East Qingchun Road,

Hangzhou 310016, Zhejiang, People's Republic of China

e-mail: hui.fan@yahoo.com
(HSCT; RR=1.08; $95 \%$ CI, 1.02-1.15). Echinocandins significantly decreased the AE-related withdrawals rate compared with triazoles $(\mathrm{RR}=0.47 ; 95 \% \mathrm{CI}, 0.33$ $0.67)$. This meta-analysis revealed that echinocandins are as effective and safe as triazoles for the prophylaxis and treatment of patients with fungal infections.

\section{Introduction}

Invasive fungal infections (IFI) have emerged as a significant cause of morbidity and mortality in immunocompromised patients, particularly those with solid tumors or hematological malignancies [1-3], solid organ transplant [4], human immunodeficiency virus (HIV) infection [5, 6], and critical illness [7, 8]. Candida albicans, Cryptococcus neoformans, Aspergillus fumigatus, and Pneumocystis jirovecii are the most well-known causes of opportunistic mycosis [9]. The mortality attributable to candidemia is in the range 30 $50 \%[10,11]$, and this rate can be as high as $89 \%$ for invasive aspergillosis [12]. Furthermore, IFI significantly extends the length of stay in hospital and cause an additional economic burden. In China, the mean hospitalization cost for patients with IFI is US\$17,000, which is significantly higher than that for patients without IFI (US\$8,500; $p=0.001$ ) [13], while in Europe, the mean total cost per patient increases to $€ 8,360$ and $€ 15,280$ for patients with possible and probable or proven invasive aspergillosis, respectively, compared with patients without invasive aspergillosis $(€ 57,750 ; p<0.001)$ [14].

Fortunately, a range of new antifungals have been developed and which demonstrated therapeutic potential over the past two decades. The echinocandins and triazoles have improved the management of IFI. The triazoles, including fluconazole, itraconazole, voriconazole, 
and posaconazole, have emerged as front-line drugs for the treatment and prophylaxis of IFI. Fluconazole and itraconazole were the first-generation triazoles in clinical practice. Fluconazole plays an excellent role in prophylaxis, empirical therapy, and the treatment of invasive candidiasis. Voriconazole is an effective and safe agent against the extended spectrum of fungal pathogens. Posaconazole has a similar antimicrobial spectrum to voriconazole, with additional activity against zygomycetes [15]. The echinocandins, such as caspofungin, micafungin, and anidulafungin, belong to a novel class of semisynthetic amphiphilic lipopeptides which can noncompetitively inhibit the synthesis of the $\beta-(1,3)$ D-glucan component of the cell wall of fungi. Also, the echinocandins have been demonstrated to be safe and effective in the treatment of disseminated candidiasis and invasive aspergillosis, including azoleresistant strains and biofilms [16]. The Infectious Diseases Society of America (IDSA) guidelines recommend fluconazole and echinocandins (anidulafungin, caspofungin, or micafungin) as the first-line choice for invasive candidemia [17]. Voriconazole is recommended as the initial therapy for invasive aspergillosis, while caspofungin, posaconazole, and itraconazole are alternatives [18].

The purpose of this meta-analysis was to compare the safety and efficacy of echinocandins with triazoles in the prophylaxis of fungal infection in high-risk patients and in the treatment of proven or probable fungal infections. The efficacy end points were treatment success, microbiological success, and breakthrough infection. The safety end points were drug-related adverse events (AEs), withdrawals due to AEs, and the all-cause mortality.

\section{Method}

Search strategies

A comprehensive search of PubMed, Embase, and the Cochrane Central Register of Controlled Trials (CENTRAL) databases from inception to July 2014 was performed. The search strategy was as follows: (echinocandin OR caspofungin OR micafungin OR anidulafungin) AND (triazole OR fluconazole OR voriconazole $\mathrm{OR}$ itraconazole $\mathrm{OR}$ posaconazole $\mathrm{OR}$ ravuconazole) AND random*. The results were further limited to human studies published in English. In addition, we searched for possible eligible studies in the references within the retrieved articles, as well as in review articles.
Study selection

Two reviewers (WJ-F and XY) independently searched the literature and examined relevant randomized controlled trials (RCTs) for further assessment. A study was considered eligible if: (1) it was an RCT, (2) it included patients with proven or probable fungal infection or those at high risk of fungal infection, (3) it compared the efficacy or safety of an echinocandin with a triazole for the prophylaxis or treatment of fungal infection. Blinded and openlabeled trials were included. Trials focusing on pharmacokinetic and/or pharmacodynamic profile, dosage form evaluations, inter-echinocandin or inter-triazole comparison, topical use, pediatric or infant studies, as well as those involving combination therapy were excluded from further analysis.

\section{Data extraction and qualitative assessment}

The same two reviewers conducted data extraction independently from eligible trials. In case of any disagreement between the reviewers, a third reviewer extracted the data and a consensus was reached. The data extraction form included the following detailed information: (1) first author, year of publication, clinical settings; (2) the number of enrolled patients and intention-to-treat (ITT); (3) antifungal agents and their doses; (4)outcomes (treatment success rate, microbiological success rate, breakthrough infection, drug-related AEs, withdrawals due to AEs, and all-cause mortality). Treatment success was defined as an endoscopy grade of 0 (zero) at the end of therapy for the treatment of esophageal candidiasis, the resolution of signs and symptoms for the treatment of other IFI, and the absence of proven, probable, or suspected systemic fungal infection through the end of prophylaxis.

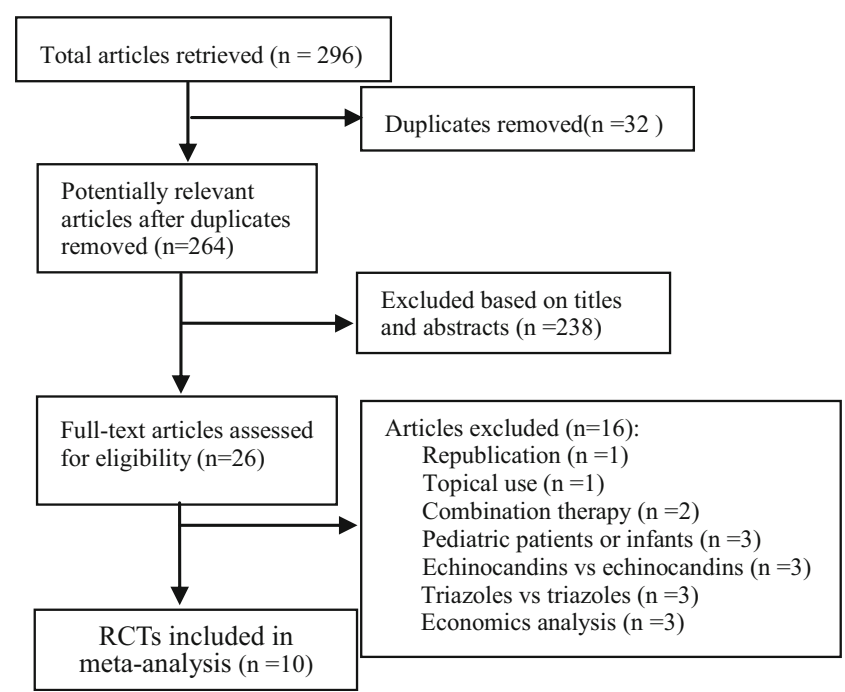

Fig. 1 Flow diagram of the selection process for the included studies 


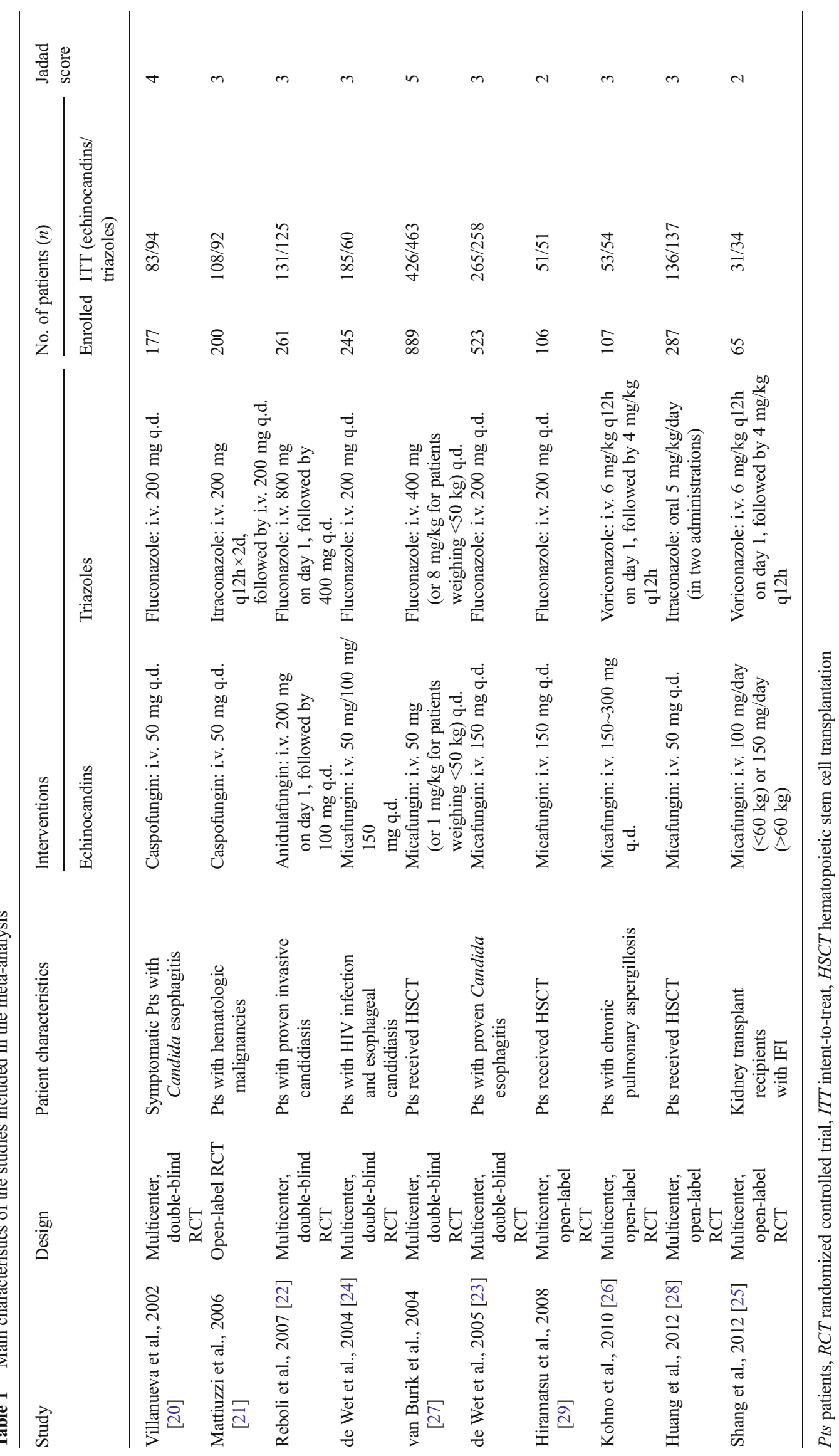


Microbiological success was defined as the eradication of Candida species and/or Aspergillus species from follow-up cultures in the treatment trials. Breakthrough infection was defined as any proven or probable IFI occurring during prophylaxis therapy. Efficacy outcomes (treatment success rate, microbiological success rate, breakthrough

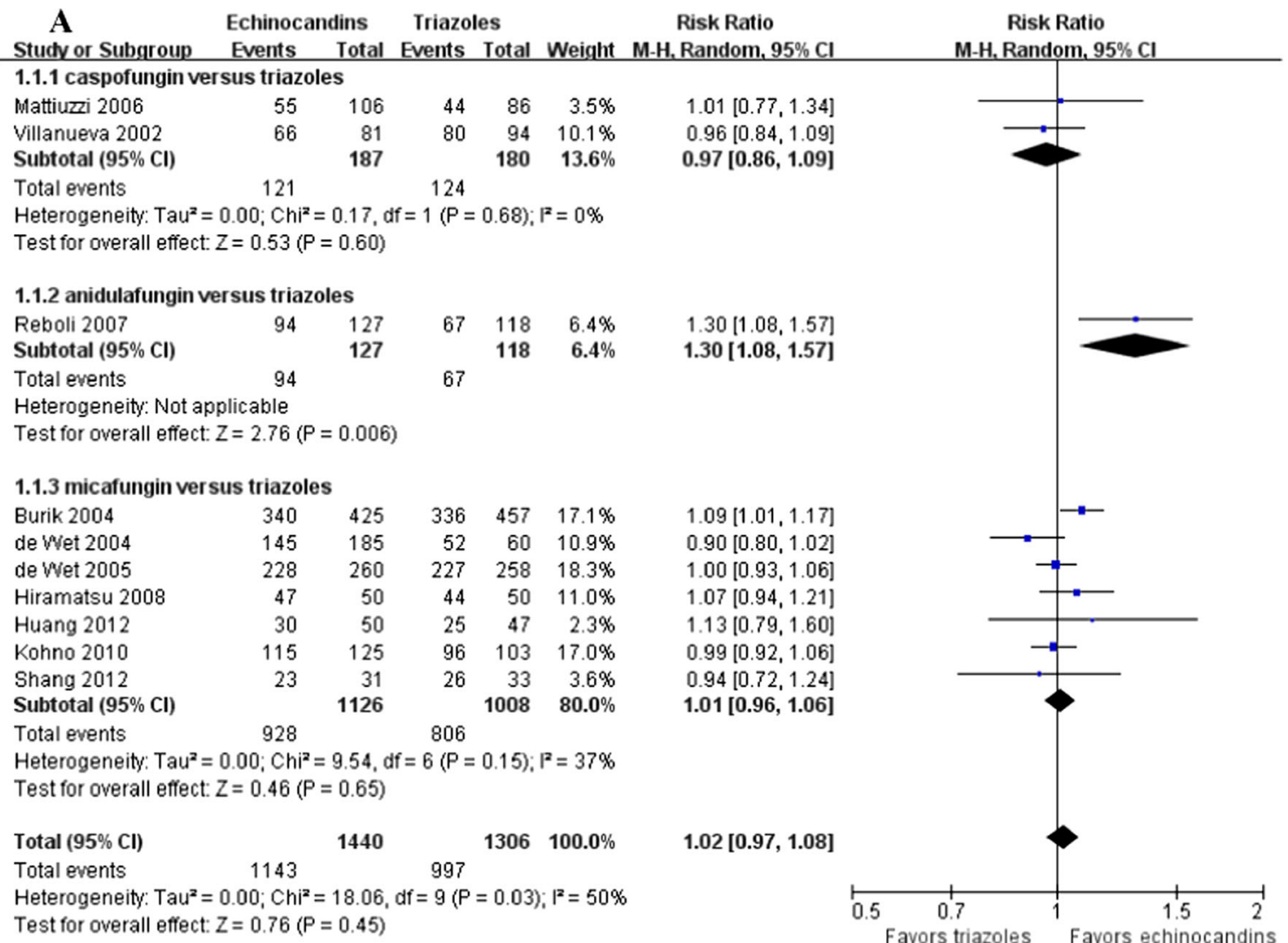

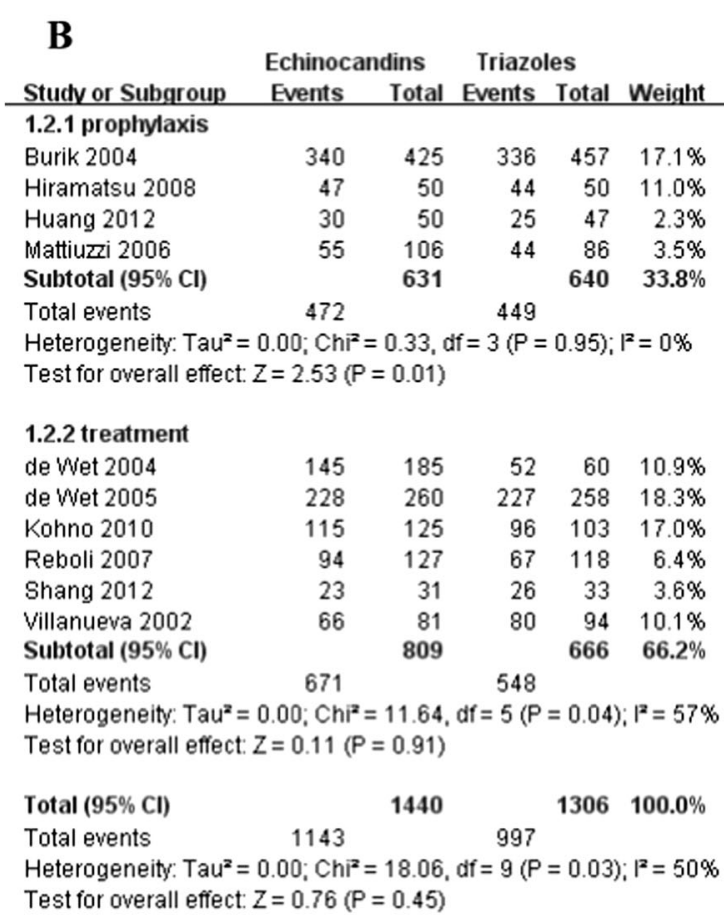

Fig. 2 Forest plot of RRs for the treatment success rate comparing echinocandins with triazoles in the prophylaxis and treatment of fungal infections. a Subgroup analysis based on various echinocandins versus
Risk Ratio

Favors triazoles Favors echinocandins

Risk Ratio

$1.09[1.01,1.17]$

$1.07[0.94,1.21]$

$1.13[0.79,1.60]$

$1.01[0.77,1.34]$

$1.08[1.02,1.15]$

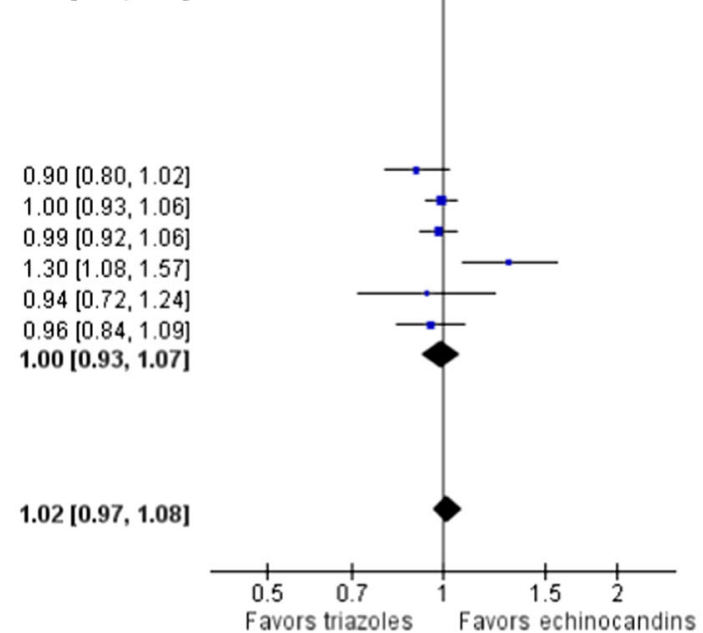

triazoles. b Subgroup analysis based on prophylaxis and treatment. $M-H$ Mantel-Haenszel, CI confidence interval 


\begin{tabular}{|c|c|c|c|c|c|c|c|c|c|}
\hline Studv or Subgroup & \multicolumn{2}{|c|}{ Echinocandins } & \multicolumn{2}{|c|}{ triazoles } & Weight & $\begin{array}{l}\text { Risk Ratio } \\
\text { H, Random, } 95 \% \mathrm{Cl}\end{array}$ & \multicolumn{2}{|c|}{$\begin{array}{c}\text { Risk Ratio } \\
\text { M-H, Random, } 95 \% \mathrm{Cl}\end{array}$} & \\
\hline de Wet 2004 & 126 & 185 & 49 & 60 & $32.1 \%$ & $0.83[0.71,0.97]$ & $\rightarrow$ & & \\
\hline Kohno 2010 & 9 & 50 & 8 & 47 & $5.8 \%$ & $1.06[0.45,2.51]$ & & & \\
\hline Reboli 2007 & 92 & 119 & 65 & 106 & $30.6 \%$ & $1.26[1.05,1.51]$ & & $\rightarrow$ & \\
\hline Villanueva 2002 & 59 & 81 & 76 & 94 & $31.5 \%$ & $0.90[0.76,1.06]$ & & & \\
\hline Total $(95 \% \mathrm{Cl})$ & & 435 & & 307 & $100.0 \%$ & $0.98[0.78,1.23]$ & & & \\
\hline Total events & 286 & & 198 & & & & & & \\
\hline $\begin{array}{l}\text { Heterogeneity. Tau }{ }^{2} \\
\text { Test for overall effec }\end{array}$ & $\begin{array}{l}0.04 ; \text { Chi }^{-} \\
Z=0.15 i\end{array}$ & $\begin{array}{l}3.06, \\
0.88)\end{array}$ & $f=3(P$ & 0.0 & $; 1^{2}=77^{\circ}$ & & $\begin{array}{ccc} & 1 & 1 \\
0.1 & 0.2 & 0.5 \\
& \text { Favors triazloes }\end{array}$ & $1 \frac{1}{2}$ & $\begin{array}{l}510 \\
\text { nocandins }\end{array}$ \\
\hline
\end{tabular}

Fig. 3 Forest plot of RRs for the microbiological success rate comparing echinocandins with triazoles in the treatment of fungal infections. $M-H$ MantelHaenszel, $C I$ confidence interval

infection) were assessed in modified ITT (mITT) patients, while safety outcomes (drug-related AEs, withdrawals due to AEs, and all-cause mortality) were analyzed in the ITT population.

The methodological quality of all included trials was assessed with the Jadad scale [19], which evaluates randomization, blinding, and the number of reported dropouts or withdrawals. The score ranges were from 0 to 5 and a trial with a score higher than 2 was considered a trial of high methodological quality.

\section{Data analysis and statistical methods}

Statistical analysis was performed using RevMan (version 5.2). Statistical heterogeneity was tested using the Cochran Q statistics generated from the $\chi^{2}$ test, and $p<0.10$ or $\mathrm{I}^{2}>50 \%$ was judged to be significant. All outcomes were recorded as dichotomous data. We calculated the pooled risk ratio (RR) and $95 \%$ confidence intervals (CIs) for all efficacy and safety outcomes using the Mantel-Haenszel fixed effects or the random-effects model according to the heterogeneity analysis. Potential publication bias was estimated by both a visual funnel plot and the Egger's test. The Egger's test was conducted with STATA software (version 12.0).

\section{Results}

Included studies and their main characteristics

Figure 1 shows a flow diagram of the process of identification and selection of the articles included in our study. Our literature search identified 296 potentially relevant abstracts. By screening the title and the abstract, 26 full-text articles were obtained, of which 16 were excluded due to the reasons mentioned earlier. Finally, ten studies [20-29] with a total of 2,837 patients were included in this analysis.

The main characteristics of the included trials are presented in Table 1. Among all of the included trials, six studies [20, 22-26] were related to the treatment of proven/probable fungal infections, while four studies [21, 27-29] were involved in the prophylaxis for high risk of fungal infections. One trial compared caspofungin with fluconazole [20], one trial compared caspofungin with itraconazole [21], one trial compared anidulafungin with fluconazole [22], four trials compared micafungin with fluconazole [23, 24, 27, 29], two trials compared micafungin with voriconazole $[25,26]$, and one trial compared micafungin with itraconazole [28]. In terms of methodology, all of the included trials were deemed to be of good quality according to the Jadad score $(\geq 2)$, with nine trials being multicenter randomized and double-blinded, and the last being randomized and openlabeled.

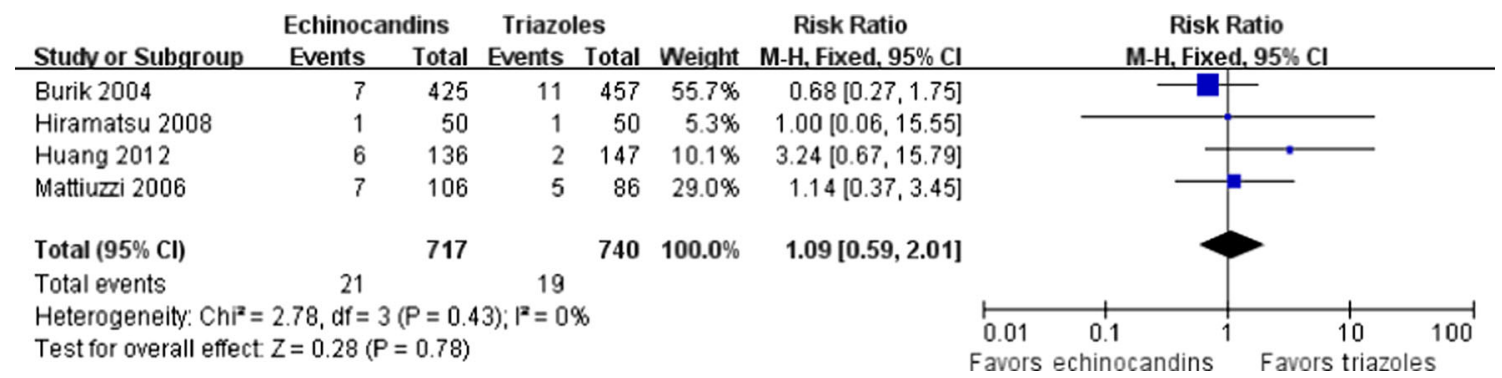

Fig. 4 Forest plot of RRs for breakthrough infection comparing echinocandins with triazoles in the prophylaxis of fungal infections. $M-H$ MantelHaenszel, $C I$ confidence interval 


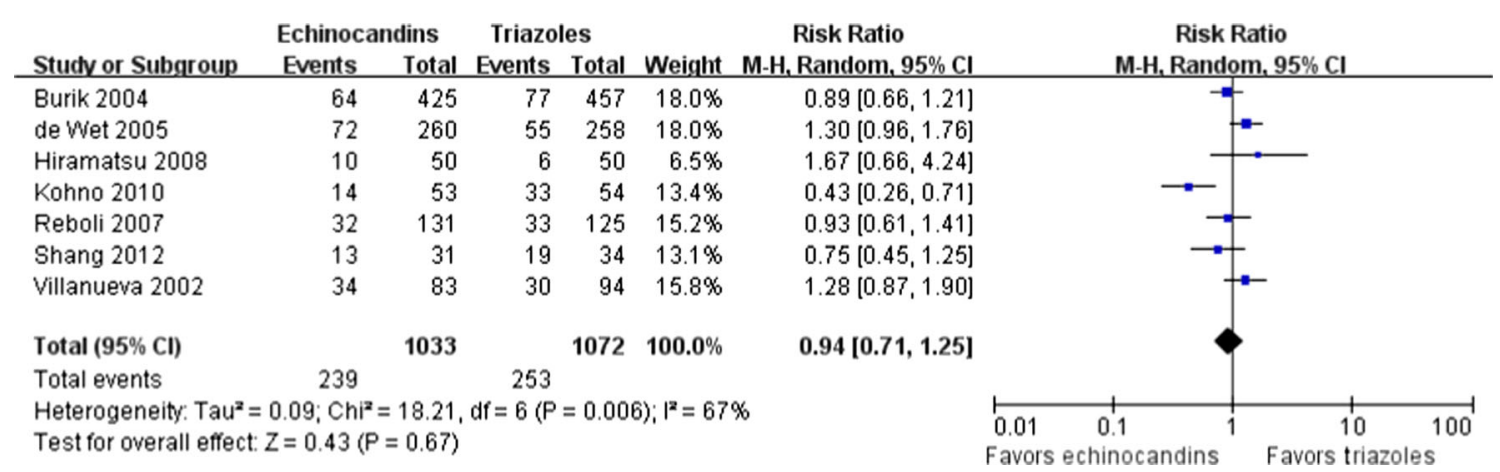

Fig. 5 Forest plot of RRs for drug-related AEs comparing echinocandins with triazoles in the prophylaxis and treatment of fungal infections. $M-H$ Mantel-Haenszel, CI confidence interval

\section{Efficacy outcomes}

All of the included studies reported the treatment success rate in the mITT population. The combined data suggested that there was no significant difference between echinocandins and triazoles in the treatment success rate (1,143/1,440 vs. 997/1,306; RR=1.02; $95 \%$ CI, 0.971.08; random effects), but obvious heterogeneity existed $\left(p=0.03, \mathrm{I}^{2}=50 \%\right)$ (Fig. 2). However, the subgroup analysis showed that echinocandins were associated with significantly higher treatment success rates than triazoles for prophylaxis in patients undergoing hematologic malignancies or those who received HSCT (671/809 vs. 548/666; RR $=1.08 ; 95 \% \mathrm{CI}, 1.02-1.15$; random effects) (Fig. 2b). For the treatment of IFI, echinocandins did not show any better treatment success than triazoles $(472 / 631$ vs. 449/640; $\mathrm{RR}=1.02 ; 95 \% \mathrm{CI}, 0.97-1.08$; random effects) (Fig. 2b). Meanwhile, the subgroup analysis indicated that caspofungin (121/187 vs. $124 / 180 ; \mathrm{RR}=$ 0.97; $95 \%$ CI, 0.86-1.09; random effects) or micafungin (928/1,126 vs. 806/1,008; RR=1.01; $95 \%$ CI, 0.961.06; random effects) was not superior to any of the triazoles (Fig. 2a). The Egger's test revealed no evidence of publication bias $(p>0.05)$.

The microbiological success rates were evaluated in four trials. Candida was the isolated pathogen in three trials [20, 22, 24] and Aspergillus in the other [26]. The pooled result showed that the microbiological success rate of echinocandins was similar to triazoles (286/435 vs. 198/307; RR=0.98; $95 \%$ CI, 0.78-1.23; random effects), and obvious heterogeneity was present $\left(p=0.005, \mathrm{I}^{2}=\right.$ $77 \%$ ) (Fig. 3). There was no significant publication bias detected when examined by the Egger's test $(p>0.05)$.

Breakthrough infection after prophylaxis of fungal infections was available in four trials, in which the high-risk patients suffered from hematologic malignancies or received hematopoietic stem cell transplantation (HSCT). The pooled RR demonstrated that echinocandins were not significantly different from triazoles in breakthrough infection $(21 / 717$ vs. $19 / 740 ; \mathrm{RR}=1.09 ; 95 \%$ CI, 0.59 2.01; fixed effects), with no statistical evidence of heterogeneity among the studies $\left(p=0.43, \mathrm{I}^{2}=0 \%\right)$ (Fig. 4). There was no significant publication bias detected according to the Egger's test $(p>0.05)$.

\section{Safety outcomes}

The rates of AEs considered possibly or probably related to treatment were reported in seven studies. There was no significant difference between echinocandins and triazoles in drug-related AEs (239/1,033 vs. 253/1,072; RR=0.94; $95 \%$ CI, 0.71-1.25; random effects), and obvious

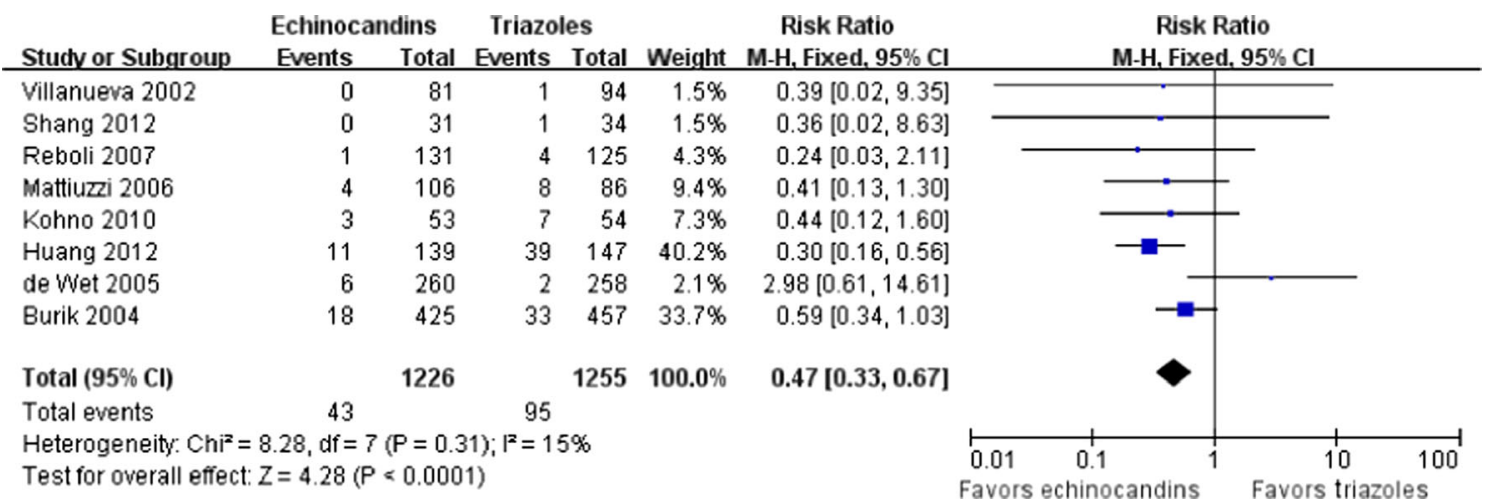

Fig. 6 Forest plot of RRs for withdrawals due to drug-related AEs comparing echinocandins with triazoles in the prophylaxis and treatment of fungal infections. $M-H$ Mantel-Haenszel, $C I$ confidence interval 
heterogeneity was found ( $p=0.006, \mathrm{I}^{2}=67 \%$ ) (Fig. 5). The Egger's test revealed no evidence of publication bias $(p>0.05)$.

Eight trials showed the proportions of patients who withdrew from the trials due to drug-related AEs. A significant difference was found between the echinocandins and triazoles groups $(43 / 1,226$ vs. $95 / 1,255 ; \mathrm{RR}=0.47 ; 95 \%$ CI, 0.33-0.67; fixed effects), and no significant heterogeneity among the studies existed ( $p=0.31, \mathrm{I}^{2}=15 \%$ ) (Fig. 6). This result indicates that echinocandins may have lower rates of patient withdrawal from treatment compared to triazoles. We recorded no publication bias with the Egger's test $(p>0.05)$.

The all-cause mortality during the therapy period was available in seven trials. However, the causes of death were rarely related to the study drugs, but, instead, to the progression of infection or complication. The overall mortality in the echinocandins group was not significantly different from that in the triazoles group $(94 / 1,086$ vs. 110/ 1,$113 ; \mathrm{RR}=0.85 ; 95 \% \mathrm{CI}, 0.66-1.10$; fixed effects), without significant heterogeneity among the studies $\left(p=0.91, \mathrm{I}^{2}=0 \%\right)$ (Fig. 7). There was no publication bias found based on the Egger's test $(p>0.05)$.

\section{Discussion}

The result of the meta-analysis by Kale-Pradhan et al. suggested that there was no significant difference in efficacy for the treatment of candidemia or invasive candidiasis between echinocandins and comparator drugs (liposomal amphotericin B, amphotericin B, and fluconazole) [30]. Caspofungin, one of the echinocandins, was also demonstrated to be as effective as other antifungal agents for the prophylaxis and treatment of fungal infections [31]. Our pooled analysis of ten RCTs with a total of 1,469 patients in the echinocandins group and 1,368 patients in the triazoles group showed similar results. It indicated that echinocandins possessed similar effects in terms of treatment success compared with triazoles in the prophylaxis and treatment of fungal infections. However, we found that echinocandins were more effective than triazoles in fungal prophylaxis by the subgroup analysis.

Micafungin is, at present, the only echinocandin approved for the prophylaxis of fungal infections in HSCT patients. Xu et al. found that micafungin was associated with a lower rate of breakthrough infection compared with fluconazole in the prophylaxis [32]. Nevertheless, we found that there was no obvious difference in breakthrough infection between echinocandins and triazoles for fungal prophylaxis. The conflict may be due to the number and type of the included trials. The trial by Hashino et al. [33] was a retrospective observational study and the trial by Hiemenz et al. [34] was associated with combination therapy, which were both excluded in our analysis. Additionally, the trial by Mattiuzzi et al. [21] associated with caspofungin was included in our review.

No differences in drug-related AEs and all-cause mortality have been found between the echinocandins and triazoles groups. Both triazoles and echinocandins have an excellent safety profile and are generally well tolerated. All triazoles have shown some degree of hepatotoxicity, ranging from mild hepatitis to cholestasis and fulminant hepatic failure [35]. Concentrations of triazoles were deemed to have no relationship with drug-related AEs. Nausea, vomiting, diarrhea, and hepatotoxicity in patients treated with triazoles may happen in the range of 5-24\% [15]. Besides, there was a $4.0-44.8 \%$ incidence of visual changes in patients receiving voriconazole [35]. Four included studies reported, in total, seven triazoles-related serious AEs [20, 22, 26]. The serious AEs in the fluconazole arm were deep-vein thrombosis, elevated levels of hepatic enzymes, and fluconazole infusion complicated cellulitis $[20,22]$. The voriconazole-related serious AEs were ventricular extra systoles, hepatic events, dizziness, and nausea. All the echinocandins patients were warned of

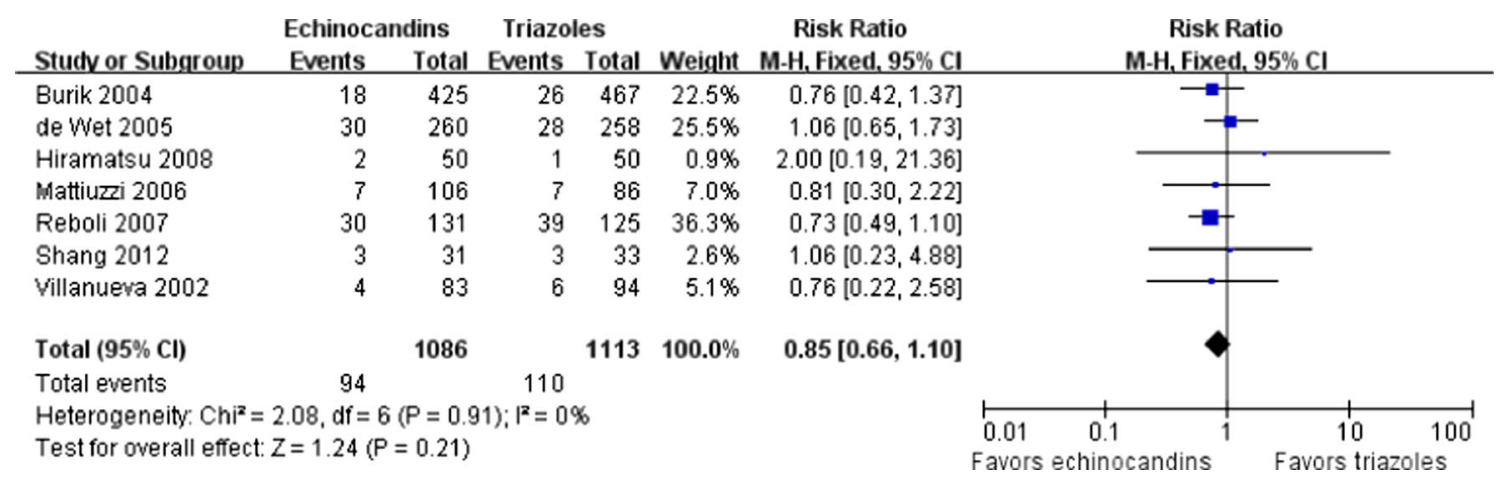

Fig. 7 Forest plot of RRs for the all-cause mortality comparing echinocandins with triazoles in the prophylaxis and treatment of fungal infections. $M-H$ Mantel-Haenszel, $\mathrm{CI}$ confidence interval 
possible hepatic dysfunction, including hepatic failure and elevated hepatic enzymes, yet the incidence was lower than that seen with the comparators [36]. In addition, rash, phlebitis, and nausea were considered to be the most frequent AEs of echinocandins. There were three echinocandins-related serious AEs reported by three included trials [22, 26], two occurred in the anidulafungin arm, including atrial fibrillation and seizures [22], and the other was disseminated intravascular coagulation because of micafungin [26].

We found that the discontinuation rate of echinocandins due to AEs was significantly lower than that of triazoles $(43 / 1,226$ vs. 95/1,255). In the triazoles groups, the discontinuation rates due to AEs of fluconazole, itraconazole, and voriconazole were about $4.3 \%$ [20, $22,23,27], 20.1 \%[21,28]$, and $9.1 \%[25,26]$, respectively, while in the echinocandins groups, the rates of caspofungin, anidulafungin, and micafungin were $2.1 \%$ [20, 21], $0.8 \%$ [22], and 4.2 [23, 25-28], respectively. Wang et al. [37] found that the pooled risks of treatment discontinuation due to adverse reactions were $13.4 \%$ for the amphotericin B formulations, $18.8 \%$ for itraconazole, $2.2 \%$ for fluconazole, $9.5 \%$ for voriconazole, $3.8 \%$ for caspofungin, $8.4 \%$ for anidulafungin, and $3.6 \%$ for micafungin.

There were several limitations in this meta-analysis. First, there was some degree of clinical heterogeneity between studies. We grouped three different echinocandins or three different triazoles together, which may lead to heterogeneity. Another potential source of heterogeneity was that we pooled together data from prophylaxis studies and treatment studies. Second, most of the included studies were associated with micafungin in the echinocandins group, only two with caspofungin, and only one with anidulafungin. As a result, the limited number of studies regarding caspofungin and anidulafungin may bias the conclusion. Most included trials were related to fluconazole in the triazoles group, while there was no RCT comparing posaconazole with echinocandins. However, Ullmann et al. found that posaconazole was superior in preventing invasive aspergillosis and reducing the rate of deaths related to fungal infections compared to fluconazole [38]. Third, the enrolled patients in the majority of trials were at high risk of mortality due to illness. When we assessed the all-cause mortality, we recognized that many patients may have died due to their original disease but not AEs. Additionally, seven trials included in this meta-analysis were industrysponsored, a factor that may generate bias in the assessment of outcomes.

In conclusion, despite the above limitations, our results suggested that echinocandins are as effective as triazoles for the prophylaxis and treatment of patients with fungal infections. However, echinocandins may be superior to triazoles for prophylaxis only. Compared to triazoles, echinocandins were found to be equally safe regarding the incidence rate of drug-related AEs, despite the fact that withdrawals due to drug-related AEs was significantly different. Further research is needed in order to compare the efficacy and safety between posaconazole and echinocandins.

Conflict of interest The authors declare that they have no conflict of interest.

Open Access This article is distributed under the terms of the Creative Commons Attribution License which permits any use, distribution, and reproduction in any medium, provided the original author(s) and the source are credited.

\section{References}

1. Neofytos D, Horn D, Anaissie E, Steinbach W, Olyaei A, Fishman J, Pfaller M, Chang C, Webster K, Marr K (2009) Epidemiology and outcome of invasive fungal infection in adult hematopoietic stem cell transplant recipients: analysis of Multicenter Prospective Antifungal Therapy (PATH) Alliance registry. Clin Infect Dis 48(3):265-273

2. Lewis RE, Cahyame-Zuniga L, Leventakos K, Chamilos G, BenAmi R, Tamboli P, Tarrand J, Bodey GP, Luna M, Kontoyiannis DP (2013) Epidemiology and sites of involvement of invasive fungal infections in patients with haematological malignancies: a 20-year autopsy study. Mycoses 56(6):638-645

3. Zirkel J, Klinker H, Kuhn A, Abele-Horn M, Tappe D, Turnwald D, Einsele H, Heinz WJ (2012) Epidemiology of Candida blood stream infections in patients with hematological malignancies or solid tumors. Med Mycol 50(1):50-55

4. Pappas PG, Alexander BD, Andes DR, Hadley S, Kauffman CA, Freifeld A, Anaissie EJ, Brumble LM, Herwaldt L, Ito J, Kontoyiannis DP, Lyon GM, Marr KA, Morrison VA, Park BJ, Patterson TF, Perl TM, Oster RA, Schuster MG, Walker R, Walsh TJ, Wannemuehler KA, Chiller TM (2010) Invasive fungal infections among organ transplant recipients: results of the TransplantAssociated Infection Surveillance Network (TRANSNET). Clin Infect Dis 50(8):1101-1111

5. Marukutira T, Huprikar S, Azie N, Quan SP, Meier-Kriesche HU, Horn DL (2014) Clinical characteristics and outcomes in 303 HIVinfected patients with invasive fungal infections: data from the Prospective Antifungal Therapy Alliance registry, a multicenter, observational study. HIV AIDS (Auckl) 6:39-47

6. de Oliveira RB, Atobe JH, Souza SA, de Castro Lima Santos DW (2014) Epidemiology of invasive fungal infections in patients with acquired immunodeficiency syndrome at a reference hospital for infectious diseases in Brazil. Mycopathologia 178(1-2):71-78

7. Guo F, Yang Y, Kang Y, Zang B, Cui W, Qin B, Qin Y, Fang Q, Qin T, Jiang D, Li W, Gu Q, Zhao H, Liu D, Guan X, Li J, Ma X, Yu K, Chan D, Yan J, Tang Y, Liu W, Li R, Qiu H; China-SCAN Team (2013) Invasive candidiasis in intensive care units in China: a multicentre prospective observational study. J Antimicrob Chemother 68(7):1660-1668

8. Shoham S, Marwaha S (2010) Invasive fungal infections in the ICU. J Intensive Care Med 25(2):78-92

9. Pfaller MA, Diekema DJ (2010) Epidemiology of invasive mycoses in North America. Crit Rev Microbiol 36(1):1-53

10. Gudlaugsson $\mathrm{O}$, Gillespie S, Lee $\mathrm{K}$, Vande Berg J, Hu J, Messer S, Herwaldt L, Pfaller M, Diekema D (2003) Attributable mortality of nosocomial candidemia, revisited. Clin Infect Dis 37(9):1172-1177 
11. Puig-Asensio M, Padilla B, Garnacho-Montero J, Zaragoza O, Aguado JM, Zaragoza R, Montejo M, Muñoz P, Ruiz-Camps I, Cuenca-Estrella M, Almirante B; CANDIPOP Project; GEIH-GEMICOMED (SEIMC); REIPI (2014) Epidemiology and predictive factors for early and late mortality in Candida bloodstream infections: a population-based surveillance in Spain. Clin Microbiol Infect 20(4):O245-O254

12. Wingard JR, Ribaud P, Schlamm HT, Herbrecht R (2008) Changes in causes of death over time after treatment for invasive aspergillosis. Cancer 112(10):2309-2312

13. Xie GH, Fang XM, Fang Q, Wu XM, Jin YH, Wang JL, Guo QL, Gu MN, Xu QP, Wang DX, Yao SL, Yuan SY, Du ZH, Sun YB, Wang $\mathrm{HH}, \mathrm{Wu}$ SJ, Cheng BL (2008) Impact of invasive fungal infection on outcomes of severe sepsis: a multicenter matched cohort study in critically ill surgical patients. Crit Care 12(1):R5

14. Slobbe L, Polinder S, Doorduijn JK, Lugtenburg PJ, el Barzouhi A, Steyerberg EW, Rijnders BJ (2008) Outcome and medical costs of patients with invasive aspergillosis and acute myelogenous leukemia-myelodysplastic syndrome treated with intensive chemotherapy: an observational study. Clin Infect Dis 47(12): 1507-1512

15. Lass-Flörl C (2011) Triazole antifungal agents in invasive fungal infections: a comparative review. Drugs 71(18):2405-2419

16. Kim R, Khachikian D, Reboli AC (2007) A comparative evaluation of properties and clinical efficacy of the echinocandins. Expert Opin Pharmacother 8(10):1479-1492

17. Pappas PG, Kauffman CA, Andes D, Benjamin DK Jr, Calandra TF, Edwards JE Jr, Filler SG, Fisher JF, Kullberg BJ, Ostrosky-Zeichner L, Reboli AC, Rex JH, Walsh TJ, Sobel JD; Infectious Diseases Society of America (2009) Clinical practice guidelines for the management of candidiasis: 2009 update by the Infectious Diseases Society of America. Clin Infect Dis 48(5):503-535

18. Walsh TJ, Anaissie EJ, Denning DW, Herbrecht R, Kontoyiannis DP, Marr KA, Morrison VA, Segal BH, Steinbach WJ, Stevens DA, van Burik JA, Wingard JR, Patterson TF; Infectious Diseases Society of America (2008) Treatment of aspergillosis: clinical practice guidelines of the Infectious Diseases Society of America. Clin Infect Dis 46(3):327-360

19. Jadad AR, Moore RA, Carroll D, Jenkinson C, Reynolds DJ, Gavaghan DJ, McQuay HJ (1996) Assessing the quality of reports of randomized clinical trials: is blinding necessary? Control Clin Trials 17(1):1-12

20. Villanueva A, Gotuzzo E, Arathoon EG, Noriega LM, Kartsonis NA, Lupinacci RJ, Smietana JM, DiNubile MJ, Sable CA (2002) A randomized double-blind study of caspofungin versus fluconazole for the treatment of esophageal candidiasis. Am J Med 113(4):294-299

21. Mattiuzzi GN, Alvarado G, Giles FJ, Ostrosky-Zeichner L, Cortes J, O'Brien S, Verstovsek S, Faderl S, Zhou X, Raad II, Bekele BN, Leitz GJ, Lopez-Roman I, Estey EH (2006) Open-label, randomized comparison of itraconazole versus caspofungin for prophylaxis in patients with hematologic malignancies. Antimicrob Agents Chemother 50(1):143-147

22. Reboli AC, Rotstein C, Pappas PG, Chapman SW, Kett DH, Kumar D, Betts R, Wible M, Goldstein BP, Schranz J, Krause DS, Walsh TJ (2007) Anidulafungin versus fluconazole for invasive candidiasis. N Engl J Med 356(24):2472-2482

23. de Wet NT, Bester AJ, Viljoen JJ, Filho F, Suleiman JM, Ticona E, Llanos EA, Fisco C, Lau W, Buell D (2005) A randomized, double blind, comparative trial of micafungin (FK463) vs. fluconazole for the treatment of oesophageal candidiasis. Aliment Pharmacol Ther 21(7):899-907

24. de Wet N, Llanos-Cuentas A, Suleiman J, Baraldi E, Krantz EF, Della Negra M, Diekmann-Berndt H (2004) A randomized, double-blind, parallel-group, dose-response study of micafungin compared with fluconazole for the treatment of esophageal candidiasis in HIVpositive patients. Clin Infect Dis 39(6):842-849
25. Shang W, Feng G, Sun R, Wang X, Liu W, Zhang S, Li J, Pang X, Wang Y, Zhang W (2012) Comparison of micafungin and voriconazole in the treatment of invasive fungal infections in kidney transplant recipients. J Clin Pharm Ther 37(6):652-656

26. Kohno S, Izumikawa K, Ogawa K, Kurashima A, Okimoto N, Amitani R, Kakeya H, Niki Y, Miyazaki Y; Japan Chronic Pulmonary Aspergillosis Study Group (JCPASG) (2010) Intravenous micafungin versus voriconazole for chronic pulmonary aspergillosis: a multicenter trial in Japan. J Infect 61(5):410-418

27. van Burik JAH, Ratanatharathorn V, Stepan DE, Miller CB, Lipton JH, Vesole DH, Bunin N, Wall DA, Hiemenz JW, Satoi Y, Lee JM, Walsh TJ; National Institute of Allergy and Infectious Diseases Mycoses Study Group (2004) Micafungin versus fluconazole for prophylaxis against invasive fungal infections during neutropenia in patients undergoing hematopoietic stem cell transplantation. Clin Infect Dis 39(10):1407-1416

28. Huang X, Chen H, Han M, Zou P, Wu D, Lai Y, Huang H, Chen X, Liu T, Zhu H, Wang J, Hu J (2012) Multicenter, randomized, openlabel study comparing the efficacy and safety of micafungin versus itraconazole for prophylaxis of invasive fungal infections in patients undergoing hematopoietic stem cell transplant. Biol Blood Marrow Transplant 18(10):1509-1516

29. Hiramatsu Y, Maeda Y, Fujii N, Saito T, Nawa Y, Hara M, Yano T, Asakura S, Sunami K, Tabayashi T, Miyata A, Matsuoka K, Shinagawa K, Ikeda K, Matsuo K, Tanimoto M; West-Japan Hematology and Oncology Group (2008) Use of micafungin versus fluconazole for antifungal prophylaxis in neutropenic patients receiving hematopoietic stem cell transplantation. Int J Hematol 88(5):588595

30. Kale-Pradhan PB, Morgan G, Wilhelm SM, Johnson LB (2010) Comparative efficacy of echinocandins and nonechinocandins for the treatment of Candida parapsilosis Infections: a metaanalysis. Pharmacotherapy 30(12):1207-1213

31. Yuan X, Wang R, Bai CQ, Song XJ, Liu YN (2012) Caspofungin for prophylaxis and treatment of fungal infections in adolescents and adults: a meta-analysis of randomized controlled trials. Pharmazie 67(4):267-273

32. Xu SX, Shen JL, Tang XF, Feng B (2013) Newer antifungal agents for fungal infection prevention during hematopoietic cell transplantation: a meta-analysis. Transplant Proc 45(1):407-414

33. Hashino S, Morita L, Takahata M, Onozawa M, Nakagawa M, Kawamura T, Fujisawa F, Kahata K, Izumiyama K, Yonezumi M, Chiba K, Kondo T, Asaka M (2008) Administration of micafungin as prophylactic antifungal therapy in patients undergoing allogeneic stem cell transplantation. Int J Hematol 87(1):91-97

34. Hiemenz J, Cagnoni P, Simpson D, Devine S, Chao N, Keirns J, Lau W, Facklam D, Buell D (2005) Pharmacokinetic and maximum tolerated dose study of micafungin in combination with fluconazole versus fluconazole alone for prophylaxis of fungal infections in adult patients undergoing a bone marrow or peripheral stem cell transplant. Antimicrob Agents Chemother 49(4):1331-1336

35. Neofytos D, Avdic E, Magiorakos AP (2010) Clinical safety and tolerability issues in use of triazole derivatives in management of fungal infections. Drug Healthc Patient Saf 2:27-38

36. Chen SC, Slavin MA, Sorrell TC (2011) Echinocandin antifungal drugs in fungal infections: a comparison. Drugs 71(1):11-41

37. Wang JL, Chang CH, Young-Xu Y, Chan KA (2010) Systematic review and meta-analysis of the tolerability and hepatotoxicity of antifungals in empirical and definitive therapy for invasive fungal infection. Antimicrob Agents Chemother 54(6):2409-2419

38. Ullmann AJ, Lipton JH, Vesole DH, Chandrasekar P, Langston A, Tarantolo SR, Greinix H, Morais de Azevedo W, Reddy V, Boparai N, Pedicone L, Patino H, Durrant S (2007) Posaconazole or fluconazole for prophylaxis in severe graft-versus-host disease. $\mathrm{N}$ Engl $\mathrm{J}$ Med 356(4):335-347 